\title{
Analysis of Bleeding Site to Identify Associated Risk Factors of Intractable Epistaxis
}

\author{
Zhenpeng Liao $\mathbb{D}^{1, *}$ \\ Jianling Guo ${ }^{l} * *$ \\ Jiaoping $\mathrm{Mi}^{1, *}$ \\ Wei Liao' \\ Shulin Chen' \\ Yili Huang' \\ Yingxiang $\mathrm{Xu}^{\prime}$ \\ Jun Zhang' \\ Qintai Yang ${ }^{2}$ \\ Haiyu Hong (D') \\ 'Allergy Center, Department of \\ Otolaryngology, The Fifth Affiliated \\ Hospital of Sun Yat-sen University, \\ Zhuhai, People's Republic of China; \\ ${ }^{2}$ Department of Otolaryngology, The \\ Third Affiliated Hospital of Sun Yat-sen \\ University, Guangzhou, Guangdong, \\ People's Republic of China \\ *These authors contributed equally to \\ this work
}

\begin{abstract}
Introduction: Intractable epistaxis refers to deep occult bleeding and uncontrolled persistent bleeding. Effective treatment can only be implemented if the bleeding site is quickly identified and the underlying disease controlled.

Objective: The relationship between the bleeding site and the pathogenic factors of intractable epistaxis was analyzed to further strengthen the prevention and treatment of intractable epistaxis by outpatient doctors, family doctors and otolaryngologists. Through accurate search and minimally invasive hemostasis, it helped optimize the treatment plan for intractable epistaxis.
\end{abstract}

Methods: This study retrospectively analyzed the clinical data of 90 patients with intractable epistaxis who were admitted to hospital from January 2016 to December 2017. Chisquare test was used to analyze the relationship between intractable epistaxis site with underlying disease, gender and age.

Results: The distribution of intractable epistaxis was associated with hypertension $\left(\chi^{2}=13.76, P=0.017\right)$. The incidence of hypertension was the highest in the olfactory sulcus of the middle turbinate region at about $60 \%$. In addition, age was also identified as a factor that affects the distribution of intractable epistaxis $\left(\chi^{2}=21.95, P=0.02\right)$. The incidence of intractable epistaxis on the vault of inferiornasal meatus region was highest $(63 \%)$ in young patients. On the other hand, the olfactory sulcus of the middle turbinate region accounted for the highest incidence in the middle-aged and elderly group (66.7\%). There was no obvious relation between the bleeding site of intractable epistaxis with diabetes, cardiovascular disease, chronic sinusitis and allergic rhinitis.

Conclusion: The bleeding site of intractable epistaxis is related to hypertension and age. This may improve the identification of the site of intractable epistaxis for timely implementation of treatment and can further strengthen the prevention and treatment of intractable epistaxis in outpatients or family doctors.

Keywords: intractable epistaxis, bleeding site, hypertension, age

\section{Introduction}

Epistaxis is one of the most common emergencies in otolaryngology, ${ }^{1}$ affecting $12 \%$ of the population each year, where around $6 \%$ to $10 \%$ of these cases require medical treatment in the hospital. ${ }^{2}$ Although the majority of nasal bleeding can be treated with conventional local compression, vasoconstrictor and nasal packing; intractable epistaxis cannot be controlled as easily due to the depth of the bleeding site, abnormal nasal anatomy, and uncontrolled persistent bleeding., ${ }^{3,4}$ Our previous study had found that the responsible arteries for intractable epistaxis are mainly the sphenopalatine artery and the anterior or posterior ethmoidal artery. The frequency 
of bleeding areas came as follows: the vault of inferior nasal meatus, the olfactory sulcus of middle turbinate, the posterior regions of middle meatus, the regions of deviation of nasal septum, the foremost regions of nasal cavity, and the others or uncertain. ${ }^{5}$ Our group has mapped the distribution of hidden bleeding sites in intractable epistaxis, which helped to optimize the treatment program for intractable epistaxis through accurate search and minimally invasive hemostasis. ${ }^{5}$ In order to further strengthen the prevention and treatment of intractable epistaxis by outpatient or family physicians, our team aimed to further explore and analyze the relationship between the bleeding site and the associated risk factors due to underlying diseases that can contribute to intractable epistaxis as a mean to improve the site identification for timely and targeted treatment procedures to be administered.

\section{Materials and Methods \\ Research Subjects}

Subjects were recruited from 90 patients with unilateral intractable epistaxis admitted to our hospital between January 2016 and December 2017, where the epistaxis was unable to be fully controlled by routine nasal packing in the outpatient clinic. The study was approved by the Ethical Committees of the Fifth Affiliated Hospitals of Sun Yat-sen University (Approved No. of ethic committee: 2021-K217-1) and conducted in accordance with the declaration of Helsinki. All patients provided written informed consent to use their clinical data. All patients underwent routine enteroscopy and no obvious bleeding was found before admission. Patients with related factors contributing to nasal bleeding, such as surgery, trauma, diseases of the blood system, and benign and malignant tumors of the nose and paranasal sinuses, were excluded.

\section{Optimized Diagnosis and Treatment of Epistaxis}

All inpatients were treated in accordance with the previous study of our team's optimized model. We utilized nasal constriction and surface anesthesia under a nasal endoscope (stoze $0^{\circ}, 1: 1000$ epinephrine $+1 \%$ tetracaine cotton tablets), and an appropriate size aspirator to remove blood accumulation or active bleeding to ensure clear vision. Displacement of middle/inferior turbinate fracture is performed if necessary. All operations were performed by senior attending physicians and associate chief physicians. Detection of bleeding site to perform the hemostasis procedure is based on the detection of i) active bleeding where the bleeding site can be determined according to the direction of blood flow; and ii) static bleeding period where key bleeding points are located in the hidden areas following the sequence of shallow to deep, simple to complex, and non-invasive to invasive. The search sequence for determining hidden bleeding points is as follows: the foremost regions of nasal cavity $\rightarrow$ the total nasal canal and septum $\rightarrow$ the posterior regions of middle meatus (middle turbinate fracture internal) $\rightarrow$ the olfactory sulcus of middle turbinate (middle turbinate fracture external) $\rightarrow$ the vault of inferiornasal meatus (inferior turbinate fracture internal). We then performed local minimally invasive hemostasis to avoid nasal congestion at the accurate bleeding site. ${ }^{5}$

\section{Epistaxis Site Classification and Factor Statistics}

The classification of epistaxis site was as follows (Figure 1): the vault of inferiornasal meatus (VIM), the olfactory sulcus of middle turbinate (OSMT), the posterior regions of middle meatus (PRMM), the regions of deviation of nasal septum (RDNS), the foremost regions of nasal cavity (FRNC), and others. ${ }^{5}$

Underlying diseases analyzed in this study include: hypertension, diabetes, cardiovascular diseases, chronic sinusitis, and allergic rhinitis.

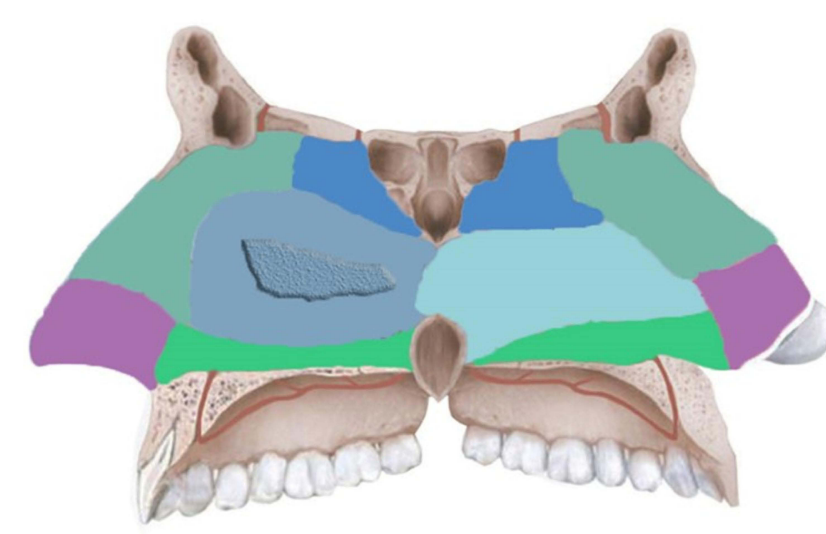

The olfactory sulcus of middle turbinate(OSMT): $58.1 \%$

The vault of inferiornasal meatus(VIM): 16.1\%

The regions of deviation of nasal septum(RDNS): $10.0 \%$

The posterior regions of middle meatus(PRMM): 6.4\%

The foremost regions of nasal cavity(FRNC): $6.4 \%$

Figure I Relationship between bleeding site and hypertension in "map". 
Another factor analyzed in this study is the age where age subgroups were proposed according to the World Health Organization (WHO) of the United Nations (UN), where they were divided into youth group $(<45$ years old), middleaged group (45-59 years old), and elderly group ( $\geq 60$ years old) ${ }^{6}$

The characteristics of the patients' age and gender with respect to the bleeding site are listed in Table 1.

\section{Statistical Analysis}

The $\chi^{2}$ test was used to analyze the association between the bleeding site and each underlying disease, age and gender by SPSS22.0 software to identify risk factors for developing epistaxis at each of the bleeding sites. Fisher's exact probability method was used for comparison between groups. $P<0.05$ was considered to be statistically significant.

\section{Results}

\section{The Relationship Between Bleeding Site and Underlying Disease}

The relationship between the bleeding site and the underlying disease of intractable epistaxis was shown in Figures 1, 2 and Tables 2, 3. Primarily, It is showed that the bleeding site of intractable epistaxis are associated with the underlying disease (Table $2, \chi^{2}=17.65$, correlation coefficient $=0.405, P=0.003$ ). Furthermore, hypertension was found in all the bleeding sites, suggesting that hypertension may be the most important

Table I Clinical Characteristics of Patients with Intractable Epistaxis

\begin{tabular}{|l|l|l|l|}
\hline Bleeding Site & Male & Female & $\begin{array}{l}\text { Age (y), } \\
\text { Mean士SD }\end{array}$ \\
\hline $\begin{array}{l}\text { The vault of inferiornasal } \\
\text { meatus }\end{array}$ & 18 & 9 & $38.2 \pm 13.0$ \\
\hline $\begin{array}{l}\text { The olfactory sulcus of middle } \\
\text { turbinate }\end{array}$ & 19 & 11 & $53.4 \pm 17.7$ \\
\hline $\begin{array}{l}\text { The posterior regions of } \\
\text { middle meatus }\end{array}$ & 7 & 2 & $48.4 \pm 13.4$ \\
\hline $\begin{array}{l}\text { The regions of deviation of } \\
\text { nasal septum }\end{array}$ & 9 & 1 & $41.5 \pm 18.7$ \\
\hline $\begin{array}{l}\text { The foremost regions of nasal } \\
\text { cavity }\end{array}$ & 4 & 3 & $50.6 \pm 12.0$ \\
\hline The others & 3 & 4 & $47.9 \pm 11.1$ \\
\hline
\end{tabular}

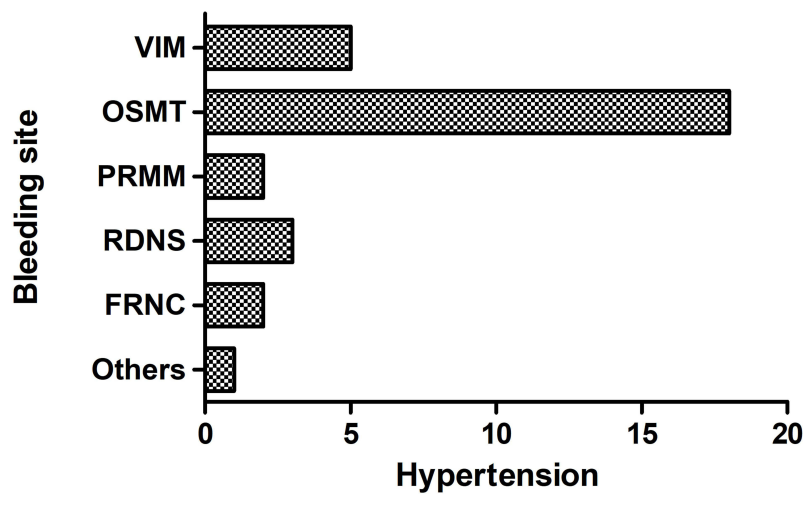

Figure 2 Relationship between bleeding site and hypertension. Abbreviations: VIM, vault of inferiornasal meatus; OSMT, olfactory sulcus of middle turbinate; PRMM, posterior regions of middle meatus; RDNS, regions of deviation of nasal septum; FRNC, foremost regions of nasal cavity.

concomitant disease associated with epistaxis episode (Table 3). Chi-square was used to test the relationship between bleeding site and hypertension $\left(\chi^{2}=13.76\right.$, correlation coefficient $=0.364, P=0.017$ ). It was important to note that the incidence of hypertension resulted in more bleeding events concentrated in the OSMT region $(60 \%)$.

On the other hand, other underlying diseases like diabetes, cardiovascular disease, chronic sinusitis and allergic rhinitis may not influence bleeding site of intractable epistaxis, where the $\chi^{2}=7.59,3.90,10.13$, and 1.35 , respectively $(P>0.05)$.

\section{The Relationship Between Bleeding Site and Age}

The relationship between the bleeding site of intractable epistaxis and age is shown in Table 4. The chi-square value was 21.95 and the correlation coefficient was 0.443 $(P=0.02)$ between the bleeding site and the age, indicating that the distribution of intractable epistaxis was correlated with age. The analysis showed that the incidence at VIM

Table 2 Relationship Between Bleeding Site and the Presence or Absence of Underlying Disease in Patients

\begin{tabular}{|l|l|l|l|l|l|l|}
\hline Group & VIM & OSMT & PRMM & RDNS & FRNC & Others \\
\hline HUD & 13 & 28 & 4 & 6 & 4 & 6 \\
\hline NUD & 14 & 2 & 5 & 4 & 3 & 1 \\
\hline
\end{tabular}

Abbreviations: VIM, vault of inferiornasal meatus; OSMT, olfactory sulcus of middle turbinate; PRMM, posterior regions of middle meatus; RDNS, regions of deviation of nasal septum; FRNC, foremost regions of nasal cavity; HUD, have underlying disease; NUD, no underlying disease. 
Table 3 Relationship Between Bleeding Site and Underlying Disease in Patients

\begin{tabular}{|l|l|l|l|l|l|}
\hline Group & Hypertension & Diabetes & Cardiovascular Diseases & Chronic Sinusitis & Allergic Rhinitis \\
\hline VIM & 5 & 0 & 2 & 3 & 3 \\
OSMT & 18 & 4 & 4 & 7 & 2 \\
PRMM & 2 & 0 & 0 & 1 & 1 \\
RDNS & 3 & 0 & 0 & 2 & 1 \\
FRNC & 2 & 1 & 0 & 0 & 1 \\
Others & I & 0 & 1 & 4 & 0 \\
\hline
\end{tabular}

Abbreviations: VIM, vault of inferiornasal meatus; OSMT, olfactory sulcus of middle turbinate; PRMM, posterior regions of middle meatus; RDNS, regions of deviation of nasal septum; FRNC, foremost regions of nasal cavity.

was the highest (63\%) in the young group; while incidence in OSMT is the highest in the middle-aged and elderly group (66.7\%).

\section{The Relationship Between Bleeding Site and Gender}

While the data from Table 1 shows that the incidence of intractable epistaxis is higher in males than in females (2:1), no significant relationship is found between the bleeding site and the gender of intractable epistaxis $\left(\chi^{2}=5.17, P=0.40\right)$.

\section{Discussion}

Epistaxis is a disease caused by a multitude of environmental and local factors (such as chronic sinusitis, allergic rhinitis, trauma, tumor and structural abnormality). In particular, systemic diseases, such as hypertension, diabetes, cardiovascular and cerebrovascular diseases, blood system diseases, and liver and kidney diseases play an important role in epitaxis episodes. ${ }^{7}$ In general, about $65-75 \%$ patients with epistaxis can be treated by their community

Table 4 Relationship Between Bleeding Site and Age

\begin{tabular}{|l|l|l|l|l|}
\hline Group & $<45 y$ & $<60 y$ & $\geq 60 y$ & Total \\
\hline The vault of inferiornasal meatus & 17 & 8 & 2 & 27 \\
\hline $\begin{array}{l}\text { The olfactory sulcus of middle } \\
\text { turbinate }\end{array}$ & 10 & 4 & 16 & 30 \\
\hline $\begin{array}{l}\text { The posterior regions of middle } \\
\text { meatus }\end{array}$ & 4 & 3 & 2 & 9 \\
\hline $\begin{array}{l}\text { The regions of deviation of nasal } \\
\text { septum }\end{array}$ & 6 & 1 & 3 & 10 \\
\hline $\begin{array}{l}\text { The foremost regions of nasal } \\
\text { cavity }\end{array}$ & 2 & 3 & 2 & 7 \\
\hline The others & 2 & 4 & 1 & 7 \\
\hline
\end{tabular}

or emergency physicians. After which, among the patients with persistent anterior epistaxis, $78-88 \%$ of them can be further controlled by a specialist otolaryngologist with packing or electrocautery. ${ }^{1,8}$ An intractable epistaxis occurs when the bleeding remains uncontrolled and is difficult to treat in clinic. In addition to the bleeding site of the intractable epistaxis being hidden, it is also liable to relapse. ${ }^{9}$ Abrich et al conducted a retrospective cohort study at the Marshfield Clinic of more than 50 potential risk factors for recurrent spontaneous epistaxis, which showed hypertension and diabetes may increase the risk of epistaxis by inducing atherosclerotic changes in the nasal vessels. ${ }^{10}$ The epistaxis study of Marin et al thought that research needed to accurately investigate the role played by underlying diseases and their treatment in the occurrence of epistaxis. ${ }^{11}$ Therefore, in order to prevent the recurrence of intractable epistaxis, accurate searching of the bleeding site under the "map" of intractable epistaxis and minimally invasive hemostasis is required. Leveraging on the mapping of the bleeding site, this study further analyzed the related risk factors of intractable epistaxis, and their association with the mapped bleeding sites, in hopes of providing assistance to community family doctors in the treatment of intractable epistaxis.

It has long been a subject of debate on the correlation and causal relationship between epistaxis and hypertension. While the causal relationship is uncertain, hypertension is known to be associated with persistent, recurrent, and severe epistaxis. ${ }^{12,13}$ Min et al screened 2768 unique studies to analyze the significant correlation between hypertension and the risk of epistaxis in his metaanalysis in $2015 .{ }^{14}$ Moreover, Acar et al found that the incidence of occult hypertension was higher in patients with epistaxis than in healthy people through a controlled clinical trial. ${ }^{15}$ In our study, we found that intractable epistaxis was also associated with hypertension. We then further showed that the OSMT bleeding site was the most 
relevant site to hypertension in intractable epistaxis. Interestingly, OSMT was also a major bleeding site found in middle-aged and elderly people. The co-finding may be due to altering elasticity and pressure of small blood vessels, as well as risk of hypertension increasing with age, both increasing chances of blood vessel ruptures. $^{12,16}$ Additionally, atherosclerosis is also an important risk factor for intractable epistaxis in patients with hypertension. ${ }^{9}$ From the anatomical perspective, the responsible vessels in the OSMT area are mainly the posterior ethmoidal artery, anterior ethmoidal artery and sphenopalatine artery. The blood pressure on these vessels is high because they are curved at right angles, which rendered them more susceptible to the risk factors identified in this study. ${ }^{17}$ Therefore, we recommend that all patients with intractable epistaxis, especially in the OSMT area, receive an outpatient or home blood pressure test to detect potential hypertension, which may be associated with increased epistaxis episodes.

While older age's association with hypertension may explain the increased prevalence in old age, epistaxis can occur at any age and has a bimodal distribution. Mangussigomes et al found that the age group of 11-20 years old and 51-70 years old constitute the two peaks of epistaxis. ${ }^{18}$ On the other hand, epistaxis is found to be less common in children under 2 years of age, where their epistaxis were often linked to head trauma. ${ }^{19}$ As seen from Tables 1-3, our study suggested that the distribution of bleeding sites in intractable epistaxis also correlated with age. The VIM area was the primary site found in young people, where anatomic abnormalities predominate, while the OSMT area was the primary site in middle-aged and elderly people, where incidence become increasingly linked to underlying diseases. Thus, vascular risk factors gradually replace anatomic factors as the associated factors of intractable epistaxis as a person aged. ${ }^{20}$ Moreover, the site of intractable epistaxis also gradually changes from the branch area of the sphenopalatine artery with relatively complex anatomical structure to the branch area of the anterior and posterior ethmoid arteries with abundant artery network with age. ${ }^{21}$

In terms of gender difference, the incidence of epistaxis was observed to be higher in male than in female, potentially due to the protective effect of estrogen. ${ }^{22}$ Estrogen has been implicated in providing protective effect in the nasal mucosa, and can also reduce the occurrence of cardiovascular disease associated with epistaxis. However, while the proportion of males with intractable epistaxis was higher than females $(2: 1)$, there was no significant difference in the bleeding site between males and females in this study.

This study is not without its limitations. The small sample size may not allow us to analyze other underlying diseases in detail other than hypertension. Therefore, further prospective, large-sample, multi-center, in-depth and rigorous studies are needed to obtain more accurate data, as well as more accurate relationships between intractable epistaxis and its associated risk factors.

In conclusion, this study described the relationship between the bleeding sites of intractable epistaxis with hypertension and age. The VIM area was mainly dominated by young people without hypertension, while the OSMT area was mainly dominated by middle-aged and elderly people with hypertension. Hence, with findings in this study, clinical assessment of the bleeding status of patients with intractable epistaxis should be accompanied by checking the history of hypertension, especially in older patients. The intractable epistaxis of OSMT area should continue to take regular anti-hypertensive medication and visit outpatients or family doctors for regular blood pressure monitoring. Clinically, it is hoped that this study will be helpful in improving the prevention and treatment of intractable epistaxis by outpatient services, family physicians and otolaryngologists. We also hoped that this study can drive future research on bleeding site association with epistaxis risk factors, to accurately and quickly identify bleeding sites for treatment and reduce hospital admission.

\section{Disclosure}

This study was supported by the National Natural Science Foundation of China (grant nos. 8207040234), Basic and Applied Basic Research Project of Zhuhai City, China (grant nos. ZH2201-7003-200002-P-WC), Guangdong Administration of Traditional Chinese Medicine Project Fund (grant nos. 20191072), and Guangdong Medical Scientific and Technological Project Fund (grant nos. A2020364). The authors report no conflicts of interest in this work.

\section{References}

1. Liu Y, Zheng C, Wei W, et al. Management of intractable epistaxis: endoscopy or nasal packing? J Laryngol Otol. 2012;126(5):482-486. doi:10.1017/S0022215112000217

2. Van Horn N, Faizy TD, Schoenfeld MH, et al. Computed tomography findings in patients with primarily unknown causes of severe or recurrent epistaxis. PLoS One. 2019;14(8):e0220380. doi:10.1371/journal. pone. 0220380 
3. Elahi MM, Parnes LS, Fox AJ, et al. Therapeutic embolization in the treatment of intractable epistaxis. Arch Otolaryngol Head Neck Surg. 1995;121(1):65-69. doi:10.1001/archotol.1995.01890010051009

4. Wei W, Lai Y, Zang C, et al. A blind area of origins of epistaxis: technical or cognitive? Eur Arch Oto Rhino Laryngol. 2018;275 (6):1501-1505. doi:10.1007/s00405-018-4983-7

5. Yang QT, Deng HY, Wang WH, et al. Distribution and treatment on intractable epistaxis in concealed sites. Chin Arch Otolaryngol Head Neck Surg. 2016;23(10):602-605.

6. World Health Organization. World Health Day 2012: Ageing and Health: Toolkit for Event Organizers. World Health Organization; 2012.

7. Seidel DU, Jacob L, Kostev K, et al. Risk factors for epistaxis in patients followed in general practices in Germany. Rhinology. 2017;55(4):312-318. doi:10.4193/Rhin17.105

8. Rafael B, Martin S, Antonius S, et al. Current approaches to epistaxis treatment in primary and secondary care. Dtsch Arztebl Int. 2018.

9. Elwany S, Ibrahim AA, Soliman AI, et al. The significance of atherosclerosis in hypertensive patients with epistaxis. J Laryngol Otol. 2018:1-4.

10. Abrich V, Brozek A, Boyle TR, et al. Risk factors for recurrent spontaneous epistaxis. Mayo Clin Proc. 2014;89(12):1636-1643. doi:10.1016/j.mayocp.2014.09.009

11. Marin E, Watelet JB, Gevaert P, et al. Severe spontaneous epistaxis: retrospective study in a tertiary ENT centre. Eur Arch Oto Rhino Laryngol. 2019;276(6):1693-1699. doi:10.1007/s00405-019-05392-x

12. Kikidis D, Tsioufis K, Papanikolaou V, et al. Is epistaxis associated with arterial hypertension? A systematic review of the literature. Eur Arch Oto Rhino Laryngol. 2014;271(2):237-243. doi:10.1007/ s00405-013-2450-z

13. Khan M, Conroy K, Ubayasiri K, et al. Initial assessment in the management of adult epistaxis: systematic review. J Laryngol Otol. 2017;131(12):1035-1055. doi:10.1017/S0022215117002031
14. Min HJ, Kang H, Choi GJ, et al. Association between hypertension and epistaxis: systematic Review and Meta-analysis. Otolaryngol Head Neck Surg. 2017;157(6):921-927. doi:10.1177/0194599817721445

15. Acar B, Yavuz B, Yildiz E, et al. A possible cause of epistaxis: increased masked hypertension prevalence in patients with epistaxis. Braz J Otorhinolaryngol. 2017;83(1):45-49. doi:10.1016/ j.bjorl.2016.01.007

16. Côrte FC, Orfao T, Dias CC, et al. Risk factors for the occurrence of epistaxis: prospective study. Auris Nasus Larynx. 2018;45 (3):471-475. doi:10.1016/j.anl.2017.07.021

17. Zou Y, Deng YQ, Xiao CW, et al. Comparison of outcomes between endoscopic surgery and conventional nasal packing for epistaxis in the posterior fornix of the inferior nasal meatus.. Pak J Medi Sci. 2015;31(6):1361-1365. doi:10.12669/pjms.316.8340

18. Mangussi-Gomes J, Enout MJR, Castro TCD, et al. Is the occurrence of spontaneous epistaxis related to climatic variables? A retrospective clinical, epidemiological and meteorological study. Acta Oto Laryngol. 2016:1-6.

19. Boscardini L, Zanetta S, Ballardini G, et al. Epistaxis in children under the age of two: possible marker of abuse/neglect? A retrospective study in North-Eastern Piedmont hospitals. Minerva Pediatr. 2013;65(1):71-75.

20. Gomes P, Salvador P, Lombo C, et al. Role of age and anticoagulants in recurrent idiopathic epistaxis. Acta Otorrinolaringol Esp. 2019.

21. Chaaban MR, Zhang D, Resto V, et al. Factors influencing recurrent emergency department visits for epistaxis in the elderly. Auris Nasus Larynx. 2017:S0385814617306107. doi:10.1016/j.anl.2017.11.010

22. Kallenbach M, Dittberner A, Boeger D, et al. Hospitalization for epistaxis: a population-based healthcare research study in Thuringia, Germany. Eur Arch Oto Rhino Laryngol. 2020;277(6):1659-1666. doi:10.1007/s00405-020-05875-2
Therapeutics and Clinical Risk Management

\section{Publish your work in this journal}

Therapeutics and Clinical Risk Management is an international, peerreviewed journal of clinical therapeutics and risk management, focusing on concise rapid reporting of clinical studies in all therapeutic areas, outcomes, safety, and programs for the effective, safe, and sustained use of medicines. This journal is indexed on PubMed Central, CAS,

\section{Dovepress}

EMBase, Scopus and the Elsevier Bibliographic databases. The manuscript management system is completely online and includes a very quick and fair peer-review system, which is all easy to use. Visit http://www.dovepress.com/testimonials.php to read real quotes from published authors. 